\title{
Clinical Presentation and Etiology of Nutritional Rickets among 0-5 Year's Children: A Prospective Observational Study in Tertiary Care Hospital, Dhaka, Bangladesh
}

Shahnaz Pervin Sumi ${ }^{1 *}$, Md. Jahangir Alam², Md. Abu Tayab ${ }^{3}$, A. S. M. Nawshad Uddin Ahmed ${ }^{4}$, Md. Shahnoor Islam ${ }^{5}$, Md. Jahid Hasan ${ }^{6}$

\author{
${ }^{1}$ Resident Medical Officer, Dhaka Shishu (Children) Hospital, SHER-E-Bangla Nagar, DHAKA, Bangladesh \\ ${ }^{2}$ Professor \& Head, Department of Paediatrics, Dhaka Shishu (Children) Hospital SHER-E-Bangla Nagar, DHAKA, Bangladesh \\ ${ }^{3}$ Associated Professor, Department of Paediatrics , Dhaka Shishu (Children) Hospital SHER-E-Bangla Nagar, DHAKA, Bangladesh \\ ${ }^{4}$ Professor \& Head, Department of Paediatrics Endocrinology and Metabolic Disorder, Dhaka Shishu (Children) Hospital SHER-E- \\ Bangla Nagar, DHAKA, Bangladesh \\ ${ }^{5}$ Registrar (Medicine), Delta Medical College Hospital, Dhaka, Bangladesh \\ ${ }^{6}$ Registrar (Medicine), Dr. Sirajul Islam Medical College Hospital Ltd., Maghbazar, Dhaka
}

DOI: $10.36347 /$ sjams.2020.v08i05.028

| Received: 30.04.2020 | Accepted: 08.05.2020 | Published: 21.05.2020

*Corresponding author: Dr. Shahnaz Pervin Sumi

Background: Nutritional rickets remains a public health problem in many countries, despite dramatic declines in the prevalence of the condition in many developed countries since the discoveries of vitamin D and the role of ultraviolet light in prevention. It is very important in treating patients with nutritional rickets to know about the clinical presentation and etiology of this disease. Aim of the study: The aim of this study was to evaluate the clinical presentation and etiology of nutritional rickets among 0-5 year's children of Bangladesh. Methods: The prospective observational study was conducted in in Dhaka Shishu (Children) Hospital, Dhaka, Bangladesh during the period from August 2015 to July 2017. Child aged 1-5 years attending in the mentioned with complaints bowing of leg and/or clinical symptoms consistent with rickets were approached. Suspected rickets cases were investigated further and total 100 cases were analyzed. Informed consent and ethical measures were ensured in each cases. Result: In this study we found, $52.22 \%$ participants were with bow leg whereas $25.56 \%$ were with knock knee, $7.78 \%$ were with sabre tibia and $16.67 \%$ were with double malleolus. On the other hand, as upper limb deformities we found $27.78 \%$ with swelling and/or widening wrists, $11.11 \%$ with craniotabes and $12.22 \%$ with wide anterior. Besides these, as other deformities we found $26.67 \%$ with rib beading, $25.56 \%$ with pectus carinatum, $26.67 \%$ with delayed growth and $21.11 \%$ with delayed dentition. In analyzing the factors of nutritional rickets we found the skin color was fair, medium and dark of $10 \%, 46.67 \%$ and $43.33 \%$ respectively. On the other hand, $73.33 \%$ child got exclusive breastfeeding for 4-6 months and 26.67 got less than 4 months. In total $40 \%$ child got sunlight exposure for more than 30 minutes/day whereas $60 \%$ got it less than 30 minutes/day. Conclusion: Our study indicates that, nutritional rickets is a significant health burden that deserves special attention. The findings of this study may be helpful for the researchers in further studies on the same issues and in the treatment procedure of nutritional rickets.

Keywords: Clinical presentation, Etiology, Nutritional rickets, bowing of leg.

Copyright @ 2020: This is an open-access article distributed under the terms of the Creative Commons Attribution license which permits unrestricted use, distribution, and reproduction in any medium for non-commercial use (NonCommercial, or CC-BY-NC) provided the original author and source are credited.

\section{INTRODUCTION}

The aim of this prospective observational study was to evaluate the clinical presentation and etiology of nutritional rickets (NR) among 0-5 year's children of Bangladesh. Nutritional rickets (NR) is a disease that afflicts children and adolescents during times of rapid growth[1]. Vitamin D deficiency and/or nutritional rickets remain prevalent in developing regions of the world and rank among the 5 most common diseases in children [2,3]. Prevalence of nutritional rickets in developed countries appears to be rising $^{3}$. Suggested reasons in the literature for its reemergence include complacency in fortifying food, changing lifestyles where children spend most of their time indoors on various forms of technology and globalization which has resulted in immigration of different peoples to different geographic locations[3]. $\mathrm{NR}$ is distinct from other types of rickets in that it is merely caused by a simple deficiency in vitamins and nutrition and thus can be easily corrected if detected 
early[4]. A growing body of literature has highlighted that NR should be viewed as having a spectrum of pathogenetic mechanisms which lie between the following three milestones[3]. On one side of the spectrum are those with classic vitamin D deficiency, as studies have found among non-supplemented breastfed infants[5], while on the other side of the spectrum are those with pure calcium deficiency, yet with normal vitamin D stores as cases from Nigeria and Bangladesh have shown[6]; and in between these two are those with marginal to low vitamin D stores and a diet deficient in calcium or high in phytates which impair intestinal absorption of dietary calcium and may be the main cause of rickets globally[3]. For last two decades, rickets has become a health concern for Bangladesh and burden with about $8 \%$ of affected child[7]. Most children with rickets develop symptoms within the first 6-12 months of age but in tropical areas where sunlight is ample, like Asia and Africa, it classically manifests during the second or the third year of life[8]. Vitamin D deficiency seems to be the key component of causing nutritional rickets in many countries of the world[9,10]. But inadequate calcium has also been demonstrated as the main etiological factor of children having rickets in several countries[11]. Inadequate ultraviolet light exposure, due to avoidance of sun light for conservative maternal clothing culture (such as, veiling), long term breast feeding without taking vitamin D fortified food, reduced intake of milk and dairy products were hypothesized as a reason of this condition. All of these result in inadequate calcium causing impaired skeletal mineralization, which is the underlying pathology of nutritional rickets[12,13]. Deficiency of both calcium (Ca) and vitamin D are prevalent in Bangladesh, which is mostly due to poor socioeconomic condition of the people. Along with other factors higher air pollution is seems to be contributing vitamin D deficiency in our country. Lack of dietary calcium also is believed to be another causal factor of nutritional rickets in Bangladesh[14]. In past few decades, several study was reported about the devastating effect rickets on children[11,12] higher incidence of recurrent pneumonia in this group of children[15]. which is a major cause of childhood mortality[16]. As a result, developing countries are facing of double burden of this disease itself and by its complicaitons[16-18]. Nevertheless, it is a matter of hope that confirm diagnosis of active rickets can be made easily with simple investigations such as radiograph and alkaline phosphatase besides clinical examination [19]. Several intervention was practiced to prevent this disease particularly NR. Vitamin D supplementation or by food fortification has proven its efficacy and safe to prevent this disease[18-20]. Moreover, it would be beneficial to prevent early than treatment in context of outcome and expense[21]. In context of fewer evidence in NR incidence and prevalence, the study was designed to assess the frequency of among suspected rickets cases in DSH, Bangladesh.

\section{OBJECTIVES \\ General Objective}

- To evaluate clinical presentation and etiology of nutritional rickets among 0-5 year's children of Bangladesh.

\section{Specific Objective}

- To find out the pattern of rickets among suspected cases in Bangladesh.

\section{Methodology \& Materials}

The prospective observational study was conducted in in Dhaka Shishu (Children) Hospital, Dhaka, Bangladesh during the period from August 2015 to July 2017. Child aged 1 to 5 years attending in the mentioned with complaints bowing of leg and/or clinical symptoms consistent with rickets were approached. Suspected rickets cases were investigated further and total 100 cases were analyzed. Proper informed consent and ethical measures were ensured in each cases. Next, biochemical and radiological investigations were done to establish rickets among clinically suspected Childs. Then, serum 25-hydroxy vitamin $\mathrm{D}[25(\mathrm{OH}) \mathrm{D}]$ level was done to identify the stratification of rickets. The diagnosis was validated upon predefined diagnostic criteria; cases fulfilling both biochemical inclusion criteria and clinical signs/symptoms or radiological signs of rickets were included. The diagnosis of rickets was made based on raised plasma alkaline phosphatase (ALP), raised serum parathyroid hormone (PTH), or low/normal serum calcium $(\mathrm{Ca})$ in clinically and radiologically consistent cases [22]. Whereas, the diagnosis of nutritional rickets is made on the basis of history, physical examination, radiographs and biochemical testing particularly serum $25(\mathrm{OH}) \mathrm{D}[22]$. The cut off value of Vitamin D deficiency was set as $<30 \mathrm{nmon} / \mathrm{l}$. To evaluate the other causes of rickets were done according to the standard guideline [22]. To verify the diagnosis of rickets and its etiology (nutritional, hereditary rickets and secondary rickets), the entire medical record (s) were carefully reviewed by the investigator. Borderline result was considered criteria of exclusion and it was replaced by another consecutive purposive sampling. The child were divided into three subtypes: nutritional rickets ( rickets with vitamin $\mathrm{D}$ deficiency), non-nutritional rickets (rickets not due to the deficiency of vitamin D or rickets due to other cause) and rickets like disease (clinically alike to rickets but not proved by investigations). In this study, ethical issues were maintained according to the Helsinki declaration and ensured that parents were not get any financial benefits from this study. Clinical presentation, biochemical and radiological reports were collected and kept recorded in separate case record form. Following, collection of all the required data, these were checked, and tabulated into the computer using the SPSS/PC software 23. 


\section{RESULT}

In this current study among 100 participants $64 \%$ were male and the rest $36 \%$ were female. So male were dominating in number. In analyzing age of the participants we found, the highest $41 \%$ participants were from 12-23 months age group. Then 29\% were from 24-35 months age group, $20 \%$ were from 36-47 months age group, $8 \%$ were from $48-59$ months age group and the rest $2 \%$ were from 60 months age group. The mean $( \pm \mathrm{SD})$ age of the participants was $29.36 \pm 13.09$ months. In analyzing the socio-economic status of the participants we found most of the cases were from urban families which was $52 \%$ and $48 \%$ were from rural areas. Besides these $32 \%$ parents were illiterate $30 \%$ parents (At least one: father/mother) were primary level educated, $26 \%$ were secondary to higher secondary level educated and $12 \%$ were graduate. On the other hand, $62 \%$ participants were found from lower class family according to their family income. Then $30 \%$ were from middle class and only $8 \%$ were from upper class families. In analyzing the diagnostic findings of the participants we found the highest $79 \%$ participants were with nutritional rickets, $11 \%$ were with non-nutritional rickets and the rest10\% were rickets-like diseases. Lastly in analyzing the spectrum of presentation of children with both the nutritional and non-nutritional rickets we found, $52.22 \%$ participants were with bow leg whereas $25.56 \%$ were with knock knee, $7.78 \%$ were with sabre tibia and $16.67 \%$ were with double malleolus. On the other hand, as upper limb deformities we found $27.78 \%$ with swelling and/or widening wrists, $11.11 \%$ with craniotabes and $12.22 \%$ with wide anterior. Besides these, as other deformities we found $26.67 \%$ with rib beading, $25.56 \%$ with pectus carinatum, $26.67 \%$ with delayed growth and $21.11 \%$ with delayed dentition. In analyzing the potential factors of nutritional rickets we found the skin color was fair, medium and dark of $10 \%, 46.67 \%$ and $43.33 \%$ respectively. On the other hand, $73.33 \%$ child got exclusive breastfeeding for 4-6 months whereas 26.67 got that for less than 4 months. Besides these we found $40 \%$ child got sunlight exposure for more than 30 minutes/day whereas $60 \%$ got it less than 30 minutes/day.

Table-I: Age and distribution of participants $(\mathrm{N}=\mathbf{1 0 0 )}$

\begin{tabular}{|c|c|c|}
\hline Age (Month) & $\mathbf{n}$ & $\mathbf{\%}$ \\
\hline $12-23$ & 41 & $41 \%$ \\
\hline $24-35$ & 29 & $29 \%$ \\
\hline $36-47$ & 20 & $20 \%$ \\
\hline $48-59$ & 8 & $8 \%$ \\
\hline 60 & 2 & $2 \%$ \\
\hline
\end{tabular}

Table-II: Socio-economic characteristics of children with suspected rickets $(\mathrm{N}=100)$

\begin{tabular}{|c|c|c|}
\hline Variables & $\mathbf{n}$ & $\%$ \\
\hline \multicolumn{3}{|c|}{ Residence } \\
\hline Urban & 52 & 52 \\
\hline Rural & 48 & 48 \\
\hline \multicolumn{3}{|c|}{ Education of parents } \\
\hline Illiterate & 32 & 32 \\
\hline Primary & 30 & 30 \\
\hline SSC-HSC & 26 & 26 \\
\hline Graduate & 12 & 12 \\
\hline \multicolumn{3}{|c|}{ Economic status (Family) } \\
\hline Lower & 62 & 62 \\
\hline Middle & 30 & 30 \\
\hline Upper & 8 & 8 \\
\hline
\end{tabular}

Table-III: Spectrum of presentation of children with rickets $(\mathbf{N}=90)$

\begin{tabular}{|l|l|c|c|}
\hline \multicolumn{2}{|c|}{ Presentation } & n & \% \\
\hline \multirow{4}{*}{$\begin{array}{l}\text { Lower } \\
\text { limb } \\
\text { deformity }\end{array}$} & Bow Leg & 47 & 52.22 \\
\cline { 2 - 4 } & Knock knee & 23 & 25.56 \\
\cline { 2 - 4 } & Sabre Tibia & 7 & 7.78 \\
\cline { 2 - 4 } & $\begin{array}{l}\text { Double } \\
\text { Malleolus }\end{array}$ & 15 & 16.67 \\
\hline \multirow{1}{*}{$\begin{array}{l}\text { Upper } \\
\text { limb } \\
\text { deformity }\end{array}$} & Swelling wrist & 25 & 27.78 \\
\cline { 2 - 4 } & Craniotabes & 10 & 11.11 \\
\hline \multirow{2}{*}{$\begin{array}{l}\text { Other } \\
\text { deformity }\end{array}$} & Wide Anterior & 11 & 12.22 \\
\cline { 2 - 4 } & $\begin{array}{l}\text { Rectus beading } \\
\text { Carinatum }\end{array}$ & 24 & 26.67 \\
\cline { 2 - 4 } & $\begin{array}{l}\text { Delayed } \\
\text { Growth }\end{array}$ & 24 & 25.56 \\
\cline { 2 - 4 } & $\begin{array}{l}\text { Delayed } \\
\text { Dentition }\end{array}$ & 19 & 21.11 \\
\hline
\end{tabular}

Table- IV: Distribution factors related to the participants $(\mathrm{N}=90)$

\begin{tabular}{|c|c|c|}
\hline Variable & $\mathrm{n}$ & $\%$ \\
\hline \multicolumn{3}{|c|}{ Skin color } \\
\hline Fair & 9 & 10 \\
\hline Medium & 42 & 46.67 \\
\hline Dark & 39 & 43.33 \\
\hline \multicolumn{3}{|c|}{ Exclusive breastfeeding } \\
\hline $\begin{array}{l}4-6 \\
\text { Months }\end{array}$ & 66 & 73.33 \\
\hline $\begin{array}{l}<4 \\
\text { Months }\end{array}$ & 24 & 26.67 \\
\hline \multicolumn{3}{|c|}{ Sunlight Exposure } \\
\hline$>30 \mathrm{~min}$ & 36 & 40 \\
\hline$\leq 30 \min$ & 54 & 60 \\
\hline
\end{tabular}

\section{DISCUSSION}

The aim of this study was to evaluate the clinical presentation and etiology of nutritional rickets among 0 to 5 year's children of Bangladesh. Nutritional rickets is acknowledged as one of the major public health concerns in the world. A high prevalence of rickets was reported in Cox's bazaar and in other 
districts of Bangladesh[22]. The main reason for nutritional deficiency rickets in Bangladesh was suggested to be calcium deficiency rather than vitamin $\mathrm{D}$ deficiency in a previous study[14]. In our study, we included 100 suspected cases of rickets and found $79 \%$ cases of nutritional deficiency rickets. In all of them, 25-hydroxy vitamin D level was deficient. Reason for the difference between this study and the aforementioned study could be attributed to sample size and study design. Deficiency of Vitamin $\mathrm{D}$ in nutritional rickets needs to be addressed as several studies reported vitamin D deficiency of $28 \%$ to $40 \%$ in infants and younger children of Bangladesh depending on the age and weight of the children[13]. Also, vitamin $\mathrm{D}$ deficiency rickets has re-emerged in many affluent industrialized countries of the world. About $11 \%$ children had rickets due to other causes rather than vitamin $\mathrm{D}$ deficiency (non-nutritional rickets) in our study[24] hydroxy vitamin D level was within normal range in this group of children and was significantly higher than nutritional deficiency rickets group ( $\mathrm{p}$ value $<0.001$ ). Non-nutritional rickets group possibly consists of hypo-calcemic rickets, hypo-phosphatemic rickets and vitamin D resistance rickets in whom Vitamin D level tends to be high[25]. Respectively $36 \%, 43 \%$ and $81 \%$ nutritional deficiency rickets children had calcium deficiency, phosphate deficiency and parathyroidhormone excess in the circulation. In contrast, an Australian vitamin D deficiency rickets surveillance study found $12 \%$ cases of calcium deficiency, $7 \%$ cases of phosphate deficiency and $49 \%$ cases of parathyroid hormone excess among 398 children of vitamin D deficiency rickets[24]. This probably was due to concomitant calcium deficiency in our subjects which led to high parathyroid hormone and low phosphate level in the blood. Consistent with findings of other studies[15] nutritional rickets were found more in younger age groups and in male children in this study. In analyzing the spectrum of presentation of children with both the nutritional and non-nutritional rickets we found, $52.22 \%$ participants were with bow leg whereas $25.56 \%$ were with knock knee, $7.78 \%$ were with sabre tibia and $16.67 \%$ were with double malleolus. On the other hand, as upper limb deformities we found $27.78 \%$ with swelling and/or widening wrists, $11.11 \%$ with craniotabes and $12.22 \%$ with wide anterior in our study. However, Karim et al.[14] found knock knee (38\%) followed by bow leg (26\%) to be the leading presentation of lower limb rickets in their study. On the other hand, a Nigerian study reported swollen wrist to be the leading sign (65\%), followed by bow leg $(60 \%)$ [26]. Our study found a higher frequency of uneducated $(32 \%)$ and less-educated parents (30\% with education between 1 to 5 years) in the suspected rickets children. Although the Cox's bazaar study found a similar picture, lesser number of parent's education year may not be associated with increased incidence of rickets[22]. Because, a Nigerian study found significantly higher education years in fathers of rachitic children. Majority of the families were running on a monthly deficit budget. Similar findings were reported by Karim and his colleagues[22]. Further carefully designed studies are needed to establish low socio-economic status as a factor of nutritional deficiency rickets. Nutritional rickets is the commonest subtype of rickets. Generally 'nutritional rickets' are found $80 \%$ to $90 \%$ among the patients with rickets. Sometimes in treating the patients, physician may be misguided or be confused by the etiology of rickets like diseases.

In this current study as potential factors we found the skin color was fair, medium and dark of $10 \%$, $46.67 \%$ and $43.33 \%$ respectively. On the other hand, $73.33 \%$ child got exclusive breastfeeding for 4-6 months whereas 26.67 got that for less than 4 months. Besides these we found $40 \%$ child got sunlight exposure for more than 30 minutes/day whereas $60 \%$ got it less than 30 minutes/day. Siddiqui noted that girls who had severe vitamin D deficiency were rarely exposed to the sun, came from lower income families and that their vitamin $\mathrm{D}$ deficiency may be related to living in smaller, crowded houses with limited internal sunlight[27]. Sedrani reported that while Saudi Arabia has an abundance of sunlight, exposure is gene-rally limited due to the high daytime temperatures, which reduce the tendency of people to go out[28]. Fida agreed with Sedrani that even though Saudi Arabia enjoys year-round sunlight, it is common for children in Central and Western Saudi Arabia to have vitamin D deficiency [29].

\section{Limitations of THE STUdy}

This was a single centered study with a small sized sample. So the findings of this study may not reflect the exact scenario of the whole country.

\section{CONCLUSION AND RECOMMENDATIONS}

Our study indicates that, nutritional rickets is a significant health burden that deserves special attention. The findings of this study may be helpful for the researchers in further studies on the same issues and in the treatment procedure of nutritional rickets. For getting more specific findings we would like to recommend for conducting more studies regarding the same issue with larger sized sample.

\section{REFERENCES}

1. Lerch $\mathrm{C}$, Meissner $\mathrm{T}$. Interventions for the prevention of nutritional rickets in term born children. Cochrane Database of Systematic Reviews. 2007, CD006164-4

2. Welch TR, Bergstrom WH, Tsang RC. Vitamin D-deficient rickets: the reemergence of a onceconquered disease. Journal of Pediatrics. 2000, 137 (2): 143-145. 10.1067/mpd.2000.109008. 
3. Wagner CL, Greer FR. Prevention of rickets and vitamin $\mathrm{D}$ deficiency in infants, children, and adolescents. American Academy of Pediatrics Section on Breastfeeding; American Academy of Pediatrics Committee on Nutrition. Pediatrics. 2008, 122 (5): 1142-1152. 10.1542/peds.20081862.

4. Allgrove J. Is nutritional rickets returning?. Archives of Disease in Childhood. 2004, 89 (8): 699-701. 10.1136/adc.2003.036780.

5. Kreiter SR, Schwartz RP, Kirkman HN, Charlton PA, Calikoglu AS, Davenport ML: Nutritional rickets in African American breast-fed infants. Journal of Pediatrics. 2000, 137 (2): 153-157. 10.1067/mpd.2000.109009.

6. Thacher TD, Fischer PR, Pettifor JM, Lawson JO, Isichei CO, Reading JC, Chan GM: A comparison of calcium, vitamin $\mathrm{D}$, or both for nutritional rickets in Nigerian children. The New England Journal of Medicine. 1999, 341 (8): 563-568. 10.1056/NEJM199908193410803.

7. Dey M, Dey SC. Calcium and Vitamin D Deficiency Situation in Bangladesh: A Review. Int J Res Rev. 2015; 2(May):281-94.

8. Thacher TD, Fischer PR, Strand MA, Pettifor JM. Nutritional rickets around the world: causes and future directions. Ann Trop Paediatr. 2006; 26(1):1-16.

9. Fraser DR. Vitamin D-deficiency in Asia. J Steroid Biochem Mol Biol. 2004; 89-90(January 1996):491-5.

10. Matsuo K, Mukai T, Suzuki S, Fujieda K. Prevalence and risk factors of vitamin D deficiency rickets in Hokkaido, Japan. Pediatr Int. 2009; 51:559-62.

11. Tom D, Thacher M., Philip R, Fischer M., John M, Pettifor M. A comparison of calcium, vitamin $\mathrm{D}$, or both for nutritional rickets in Nigerian children. N Engl J Med. 1999; 341(8):563-8.

12. Pettifor J. Nutritional Rickets: Deficiency of Vitamin D, Calcium or Both? Am J Clin Nutr. 2004; 80:17255-95.

13. Roth DE, Shah MR, Black RE, Baqui AH. Vitamin D status of infants in northeastern rural Bangladesh: Preliminary observations and a review of potential determinants. J Heal Popul Nutr. 2010; 28(5):458-69.

14. Fischer PR, Rahman A, Cimma JP, Kyaw-Myint TO, Kabir ARML, Talukder K. Nutritional rickets without vitamin $\mathrm{D}$ deficiency in Bangladesh. J Trop Pediatr. 1999; 291-3.

15. Haider N, Nagi AG, Khan KMA. Frequency of nutritional rickets in children admitted with severe pneumonia. J Pak Med Assoc. 2010;60(9):729-32.

16. Aziz TK, Lehrasab W, Ahmed N, Batool Z. Frequency of Nutritional Rickets in Children 2-
59 Months of Age with Severe Pneumonia Khawaja. Ann Pak Inst Med Sci. 2016; 12(2):105-8.

17. Jones HL, Jammeh L, Owens S, Fulford AJ, Moore SE, Pettifor JM. Prevalence of ricketslike bone deformities in rural Gambian children. Bone. 2015; 77:1- 5 .

18. Robinson PD. The re-emerging burden of rickets: a decade of experience from Sydney. Arch Dis Child. 2005; 91(7):564-8.

19. Strand MA, Perry J, Jin M, Tracer DP, Fischer PR, Zhang P, Xi W. Diagnosis of rickets and reassessment of prevalence among rural children in northern China. Pediatr Int. 2007; 49(2):202-9.

20. Tau C, Ciriani V, Scaiola E, Acu nna M. Twice single doses of 100,000 IU of vitamin D in winter is adequate and safe for prevention of vitamin $\mathrm{D}$ deficiency in healthy children from Ushuaia, Tierra Del Fuego, Argentina. Journal of Steroid Biochemistry \& Molecular Biology. 2007; 103: 651-654.

21. Thacher TD, Fischer PR, Pettifor JM, Lawson JO, Isichei CO, Chan GM. Case-control study of factors associated with nutritional rickets in Nigerian children. J Pediatr. 2000; 137(3):36773.

22. Munns CF, Shaw N, Kiely M, Specker BL, Thacher TD, Ozono K. Global Consensus Recommendations on Prevention and Management of Nutritional Rickets. J Clin Endocrinol Metab. 2016; 101(2):394-415.

23. Karim F, Chowdhury AM, Gani MS. Rapid assessment of the prevalence of lower limb clinical rickets in Bangladesh. Public Health. 2003; 117:135-44.

24. Munns CF, Simm PJ, Rodda CP, Garnett SP, Zacharin MR, Ward LM. Incidence of vitamin D deficiency rickets among Australian children: An Australian Paediatric Surveillance Unit study. Med J Aust. 2012; 196(7):466-8.

25. Sahay M, Sahay R. Rickets-vitamin D deficiency and dependency. Indian $\mathbf{J}$ Endocrinol Metab. 2012 Mar; 16(2): 164- 76. [cited 2017 Dec 10]

26. Ekanem EE, Bassey DE, Eyong M. Nutritional rickets in Calabar, Nigeria. Ann Trop Paediatr. 1995; 15:303-6.

27. Siddiqui AM, Kamfar HZ. Prevalence of vitamin $\mathrm{D}$ deficiency rickets in adolescent school girls in Western region, Saudi Arabia. Saudi Med J. 2007; 28:441-4.

28. Sedrani SH. Low 25-hydroxyvitamin D and normal serum calcium concentration in Saudi Arabia, Riyadh region. Ann Nutr Metabol. 1984; 28:181-5.

29. Fida NM. Assessment of nutritional rickets in Western Saudi Arabia. Saudi Med J. 2003; 24:337- 40 . 